\title{
Research on the Integration of Study Travel Courses in Heyuan Under the Background of Cultural and Tourism Integration
}

\author{
Wu Xinlei ${ }^{1, a^{*}}$, Xu Pei ${ }^{2, b}$, Huang Juan ${ }^{3, c}$ \\ ${ }^{1}$ Faculty of Business Administration, Heyuan Polytechnic, Heyuan City, Guangdong Province, China \\ ${ }^{2}$ Faculty of Business Administration, Heyuan Polytechnic, Heyuan City, Guangdong Province, China \\ ${ }^{3}$ Faculty of Business Administration, Heyuan Polytechnic, Heyuan City, Guangdong Province, China \\ $a^{*} 1222088778 @ q q . c o m$ \\ b1393498610@qq.com \\ c853108076@qq.com
}

\begin{abstract}
In the context of the integration of culture and tourism, study travel is a new star in the cross-border integration of the education field and the tourism industry. The "Opinions on Promoting Primary and Secondary School Student Research Travel" jointly issued by 11 departments including the Ministry of Education has been published. The study travel course can be described as Like bamboo shoots after a rain, they spring up in endlessly. Based on the study travel market in Heyuan, this article investigates the development status of study travel courses in Heyuan, compares and analyzes the typical study travel courses in this city, and puts forward feasibility suggestions, in order to encourage diversified curriculum development subjects to carry out high-quality reforms on the study travel courses.
\end{abstract}

Keywords: Study travel, curriculum integration, cultural and tourism integration, Heyuan City

\section{文旅融合背景下河源研学旅行课程整合情况研究}

\section{伍新蕾 $1, \mathrm{a}$ 徐沛 $2, \mathrm{~b}$ 黄娟 $3, \mathrm{c}$}

\author{
${ }^{2}$ 河源职业技术学院工商管理学院，河源，广东，中国 \\ ${ }^{2}$ 河源职业技术学院工商管理学院，河源，广东，中国 \\ 3 河源职业技术学院工商管理学院, 河源, 广东, 中国 \\ a1222088778@qq.com \\ b1393498610@qq.com \\ c853108076@qq.com
}

\section{摘要}

在文化和旅游融合的大背景下, 研学旅行作为教育领域与旅游行业跨界融合的新星, 自教育部等 11 个部门联 合印发的《关于推进中小学生研学旅行的意见》出台, 研学旅行课程可谓如雨后春笋一般层出不穷。本文立足 于河源研学旅行市场, 围绕河源市研学旅行课程开发现状展开调研, 对本市典型的研学旅行课程进行对比分析 并提出可行性建议，以期促使多元课程开发主体对研学旅行课程进行高质量改革。

关键词：研学旅行；课程整合；文旅融合；河源 


\section{1. 引言}

近年来，国家和各省份都出台了一系列支持鼓励 研学旅行发展的政策文件。2016 年 11 月 30 日, 教 育部、国家发展改革委等 11 部门以教基一〔2016〕8 号印发《关于推进中小学生研学旅行的意见》, 《意 见》明确要求各地中小学依据本地区域情况, 将研学 旅行纳入学校的教育教学计划当中, 开发具有育人效 果的研学旅行活动课程, 实现研学旅行与学校课程的 有机融合。此文件的下发, 将中小学研学旅行的地位 提到了新的高度, 体现出国家对于研学旅行课程的重 视程度。

研学旅行作为综合实践活动课程是丰富基础教 育课程体系、推动素质教育、创新人才培养模式, 培 养学生综合素养的有效途径。从研学旅行课程的理论 研究层面, 目前处于起步阶段, 还未形成完整的理论 体系 ${ }^{[1]}$ 。从研学旅行课程的实践层面, 当前处于持续 探索和逐步提升阶段 ${ }^{[2]}$ 。文旅融合是当前旅游业的主 旋律, 研学旅行是旅游业的新业态 ${ }^{[3]}$, 在文旅融合的 大趋势下, 研学课程的实践开发愈加重视课程内容的 文化渗透。当前学术界主要通过实例对地质地理、自 然生态、学科知识、红色传统等主题课程进行研究, 已有学者对非遗文化、海洋主题课程进行研讨, 也有 少量学者围绕研学课程开发进行策略与方法、原则与 目标、价值与意义等研究。此外, 学术界对文化类研 学课程的探索主要集中在地区地域文化、红色革命文
化、历史传统文化、乡土乡情文化中，少量学者聚焦 于古镇文化、汉字文化、中医药健康旅游文化等研学 课程的探究。总体来看, 在文旅融合的背景下进行研 学旅行课程开发研究与日俱增。因此, 本文基于河源 研学课程开发的现状调研, 从文旅融合视角对河源研 学旅行课程整合情况进行探究, 为研学课程产品优化 提供指引, 助力河源市研学业态高质量健康发展。

\section{2. 河源市研学旅行课程开发概况}

河源市是广东省地域文化资源特色鲜明的地区, 旅游资源文化性显著，依托于自然人文遗产，能提炼 出远古恐龙文化、历史名人文化、山水生态文化、东 江客家文化等深遂文化, 类型多样的文化资源, 互补 性强, 空间组合较好 ${ }^{[4]}$ 。通过实地访谈调查、文献资 料研究等发现，在河源市相关政府单位的指引下，本 土文旅企事业单位、研学机构纷纷对河源研学资源进 行梳理整合及完善提升，积极开发出各类具有地方文 旅特色的研学旅行课程, 涵盖地理类、自然类、历史 类、科技类、人文类、体验类等多种类型。在 2020 年至 2021 年河源研学精品课程、教材的系列评选活 动的促进下, 本土研学课程在原创实用性、设置科学 性、体验安全性、系统教育性、主体突出性、特色鲜 明性等方面有了显著的提升。受篇幅限制, 仅选取部 分代表性课程展示如下（见表 1)。

表 1 河源市代表性研学旅行课程概况表

\begin{tabular}{|c|c|c|c|}
\hline 课程类别 & 课程名称 & 课程来源 & 课程荣誉 \\
\hline \multirow[t]{2}{*}{ 地理类 } & $\begin{array}{c}\text { 《黄龙岩研学旅行方案・领略峹族 } \\
\text { 风情破解溶洞奥秘》 } \\
\text { 地理探秘研学课程 }\end{array}$ & 广东黄龙岩㓱族风情旅游区 & $\begin{array}{l}2020 \text { 河源特色 “研学旅行-客家文化精品课程” } \\
\text { 发展潜力课程奖; } 2020 \text { 河源市美丽乡村研学旅 } \\
\text { 行实践地精品教材三等奖 }\end{array}$ \\
\hline & $\begin{array}{c}\text { 《探访霍山之丹霞红土壤的秘密一 } \\
\text { 地质文化》 }\end{array}$ & 霍山风景区 & $\begin{array}{l}2020 \text { 河源市美丽乡村研学旅行实践地精品教 } \\
\text { 材二等奖 }\end{array}$ \\
\hline \multirow{4}{*}{ 自然类 } & $\begin{array}{l}\text { 《逆流而上・寻源万绿湖》 } \\
\text { 水资源研学课程 } \\
\end{array}$ & $\begin{array}{c}\text { 河源 } \\
\text { 万绿湖风景区 }\end{array}$ & $\begin{array}{l}2020 \text { 河源市美丽乡村研学旅行实践地精品教 } \\
\text { 材一等奖 }\end{array}$ \\
\hline & $\begin{array}{l}\text { 《快乐农耕 水环境知识科普讲堂 } \\
\text { 一叶一世界》自然探究研学课程 }\end{array}$ & 万绿谷旅游度假区 & $\begin{array}{l}2020 \text { 河源市美丽乡村研学旅行实践地精品教 } \\
\text { 材三等奖 }\end{array}$ \\
\hline & $\begin{array}{c}\text { 《博物调研家》 } \\
\text { 温泉文化研学课程 } \\
\end{array}$ & \begin{tabular}{|c|} 
广东客天下研学旅行管理有 \\
限公司 \\
\end{tabular} & \\
\hline & $\begin{array}{l}\text { 《与龙共舞, 自然同行》 } \\
\text { 恐龙文化研学课程 }\end{array}$ & \begin{tabular}{|c|} 
广东客天下研学旅行管理有 \\
限公司 \\
\end{tabular} & \\
\hline \multirow{5}{*}{ 历史类 } & $\begin{array}{l}\text { 《探寻 “五兴龙” 革命历史、传承 } \\
\text { 红色基因-体会党百年历程、感悟真 } \\
\text { 理的力量》红色研学课程 } \\
\end{array}$ & \begin{tabular}{|c|} 
广东霍仙峰旅游景区股份有 \\
限公司 \\
\end{tabular} & 2021 年河源 “红色研学主题精品课程” 一等 \\
\hline & $\begin{array}{l}\text { 《传承红色基因・砥砺奋进新时代”, } \\
\text { 红色党建活动课程》红色研学课程 }\end{array}$ & \begin{tabular}{|c|} 
河源市弘霞客红色教育培训 \\
服务有限公司 \\
\end{tabular} & 2021 年河源 “红色研学主题精品课程” 二等 \\
\hline & $\begin{array}{l}\text { 《文旅相融, “红”“绿”相汇一 } \\
\text { 红色河源研学之旅》红色研学课程 }\end{array}$ & \begin{tabular}{|c|} 
河源职业技术学院 \\
学生团队 \\
\end{tabular} & 2021 年河源 “红色研学主题精品课程” 三等 \\
\hline & $\begin{array}{l}\text { 《“探寻红色, 情投义合” 河源义 } \\
\text { 合红色文化之旅》红色研学课程 }\end{array}$ & \begin{tabular}{|c|} 
广东省竹里馆旅游开发有限 \\
公司 \\
\end{tabular} & $\begin{array}{l}2021 \text { 年河源 “红色研学主题精品课程” 特色稓 } \\
\text { 程设计奖 }\end{array}$ \\
\hline & $\begin{array}{l}\text { 《“重走革命先烈路・立志争当好 } \\
\text { 少年” 河源连平大湖一日红色研学 }\end{array}$ & \begin{tabular}{|c|} 
广东河源优卓研学旅行教育 \\
发展有限公司 \\
\end{tabular} & $\begin{array}{l}2021 \text { 年河源 “红色研学主题精品课程” 特色课 } \\
\text { 程设计奖 }\end{array}$ \\
\hline
\end{tabular}




\begin{tabular}{|c|c|c|c|}
\hline & 活动方案》红色研学课程 & & \\
\hline & $\begin{array}{c}\text { 《审计风云, 观阮啸仙的一生》 } \\
\text { 红色研学课程 }\end{array}$ & 阮啸仙故居 & \\
\hline & $\begin{array}{c}\text { 《追寻红色足迹, 争当有梦少年》 } \\
\text { 红色研学课程 }\end{array}$ & 河源市博物馆 & \\
\hline & $\begin{array}{l}\text { 《践行红色文化, 做新时代爱国有 } \\
\text { 为学生》红色研学课程 }\end{array}$ & 河源市埔前镇上村村 & \\
\hline \multirow{3}{*}{ 科技类 } & $\begin{array}{c}\text { 《探秘农夫山泉, } \\
\text { 寻源万绿湖》工业研学课程 }\end{array}$ & 农夫山泉研学基地 & \\
\hline & $\begin{array}{l}\text { 《飞向北京, 飞向未来》 } \\
\text { 航模主题研学课程 }\end{array}$ & 河源市航模协会 & \\
\hline & $\begin{array}{c}\text { 《饮水思源, 我是水力发电操作员》| } \\
\text { 工业研学课程 }\end{array}$ & 新丰江水电站 & \\
\hline \multirow{7}{*}{ 人文类 } & $\begin{array}{c}\text { 《探究客家古邑, 传承客家文化》 } \\
\text { 客家文化研学课程 }\end{array}$ & $\begin{array}{c}\text { 广东司南研学教育科技有限 } \\
\text { 公司 }\end{array}$ & $\begin{array}{l}2020 \text { 河源特色 “研学旅行-客家文化精品课程” } \\
\text { 一等奖 }\end{array}$ \\
\hline & $\begin{array}{c}\text { 《研学古邑龙川・探究红色客家》 } \\
\text { 客家文化研学课程 }\end{array}$ & $\begin{array}{c}\text { 河源市集结号教育咨询有限 } \\
\text { 公司 }\end{array}$ & $\begin{array}{l}2020 \text { 河源特色 “研学旅行-客家文化精品课程” } \\
\text { 二等奖 }\end{array}$ \\
\hline & $\begin{array}{c}\text { 《河源客天下客家文化精品课程》 } \\
\text { 客家文化研学课程 }\end{array}$ & \begin{tabular}{|c|} 
广东客天下研学旅行管理有 \\
限公司
\end{tabular} & $\begin{array}{l}2020 \text { 河源特色 “研学旅行-客家文化精品课程” } \\
\text { 三等奖 }\end{array}$ \\
\hline & $\begin{array}{l}\text { 《2020 研学线路一一走进林寨稻花 } \\
\text { 香里》客家文化研学课程 }\end{array}$ & 河源市客之旅旅行社 & $\begin{array}{l}2020 \text { 河源特色 “研学旅行-客家文化精品课程” } \\
\text { 内容创新课程奖 }\end{array}$ \\
\hline & $\begin{array}{c}\text { 《客家文化研学旅行——绿油之古 } \\
\text { 法压窑茶油》 } \\
\text { 非遗体验研学课程 }\end{array}$ & $\begin{array}{c}\text { 绿油农业发展有限 } \\
\text { 公司 }\end{array}$ & $\begin{array}{l}2020 \text { 河源特色 “研学旅行-客家文化精品课程” } \\
\text { 发展潜力课程奖 }\end{array}$ \\
\hline & \begin{tabular}{|c|} 
《品见・客家》 \\
客家文化研学课程
\end{tabular} & \begin{tabular}{|c|} 
广东客天下研学旅行管理有 \\
限公司
\end{tabular} & $\begin{array}{l}2020 \text { 河源市美丽乡村研学旅行实践地精品教 } \\
\text { 材二等奖 }\end{array}$ \\
\hline & $\begin{array}{c}\text { 《重温科举文化 弘扬尊师重教》 } \\
\text { 传统文化研学课程 }\end{array}$ & 佗城景区 & $\begin{array}{l}2020 \text { 河源市美丽乡村研学旅行实践地精品教 } \\
\text { 材优秀奖 }\end{array}$ \\
\hline \multirow{6}{*}{ 体验类 } & $\begin{array}{l}\text { 《小知青探秘研学课程》 } \\
\text { 生活体验研学课程 }\end{array}$ & 四季丰研学基地 & $\begin{array}{l}2020 \text { 河源特色 “研学旅行-客家文化精品课程” } \\
\text { 发展潜力课程奖; } 2020 \text { 河源市美丽乡村研学旅 } \\
\text { 行实践地精品教材优秀奖 }\end{array}$ \\
\hline & $\begin{array}{c}\text { 《下乡三农体验, 助力乡村振兴》 } \\
\text { 劳动教育研学课程 }\end{array}$ & $\begin{array}{l}\text { 仙坑古村 } \\
\text { 研学实践基地 }\end{array}$ & $\begin{array}{l}2020 \text { 河源市美丽乡村研学旅行实践地精品教 } \\
\text { 材三等奖 }\end{array}$ \\
\hline & $\begin{array}{c}\text { 《劳动最光荣》 } \\
\text { 劳动教育研学课程 } \\
\end{array}$ & $\begin{array}{l}\text { 双头耕育田园 } \\
\text { 青少年研学基地 }\end{array}$ & \\
\hline & $\begin{array}{c}\text { 《走进福源果场, 研学农耕文化》 } \\
\text { 劳动教育研学课程 } \\
\end{array}$ & 福源果场 & \\
\hline & \begin{tabular}{c|} 
《景区 CEO》 \\
职业体验研学课程 \\
\end{tabular} & \begin{tabular}{|c|} 
广东客天下研学旅行管理有 \\
限公司
\end{tabular} & \\
\hline & $\begin{array}{l}\text { 《小兵突击・少年有梦研学夏令营》| } \\
\text { 青少年综合素质教育研学课程 }\end{array}$ & 兵王集结号基地 & \\
\hline
\end{tabular}

\section{3. 河源市典型研学旅行课程的对比分析}

河源研学旅行课程因地制宜, 类型多元, 以客家 文化、水源科考、恐龙探秘、农耕体验、红色熏陶等 主题课程最具河源特色（见表 2)。其中, 广东客天 下研学旅行管理有限公司依托客天下省级中小学生 研学实践教育基地, 借助水晶温泉旅游区、醉蝶谷、 恐龙主题乐园、客家小镇等场地与设施设备, 通过专 业的研学导师团队落地多种类研学课程; “全国乡村 旅游重点村”- - 仙坑古村积极响应国家倡导的乡村 振兴政策, 精准把握研学课程开发指引, 顺应时势打 造课程, 以具有较高的教育性、实践性与公益性的“孩
子下乡, 体验三农, 助力振兴” 为课程要旨, 获得政 府、社会各界高度的关注与支持。仙坑古村从 2019 年 3 月至 2020 年 1 月共接待学生 50000 余人次, 其 中 $80 \%$ 属于珠三角地区中小学生, 2020 年 9 月至 2021 年疫情稳定期间, 共接待学生 13000 余人次, 其中 $90 \%$ 为本地中小学生; “河源生态旅游名片” ——万 绿湖风景区以 “水” 为主旋律, 通过寻根溯源的方式, 引导孩子们从日常生活出发, 检测水源地水质、探索 水源地生态文化、探秘水源地动植物等, 增强孩子们 环保意识, 激发大家的探究精神。此外, 河源红色研 学课程实施地多为客家乡村, 因此该历史类研学课程 往往以红色文化研学为主, 并融入客家乡村生活体 验、劳动实践等环节。 
表 2 河源典型研学旅行课程内容简述表

\begin{tabular}{|c|c|c|}
\hline 课程类型 & 课程名称 & 课程概况 \\
\hline 地理类 & $\begin{array}{l}\text { 广东黄龙岩會族风情旅 } \\
\text { 游区一一《领略會族风 } \\
\text { 情・破解溶洞奥秘》 }\end{array}$ & $\begin{array}{l}\text { (1)认识會族乡: 认识畣族, 了解畣族特点及民族文化。 } \\
\text { (2)非遗卫士: 认识、体验省级非遗 “蓝大将军出巡节”。 } \\
\text { (3)溶洞奇幻记: 参观黄龙岩溶洞, 了解溶洞形成的原理, 模拟溶洞形成实验。 }\end{array}$ \\
\hline \multirow{3}{*}{ 自然类 } & $\begin{array}{l}\text { 广东客天下研学旅行管 } \\
\text { 理有限公司—— } \\
\text { 《博物调研家》 }\end{array}$ & $\begin{array}{l}\text { (1)在温泉小镇了解温泉、水晶的形成原因与条件, 进行碘伏测水质实验。 } \\
\text { (2)在醉蝶谷绿色庄园进行植物探秘, 制作 DIY 拓印画与图谱。 }\end{array}$ \\
\hline & $\begin{array}{l}\text { 广东客天下研学旅行管 } \\
\text { 理有限公司一一 } \\
\text { 《与龙共舞, 自然同行》 }\end{array}$ & $\begin{array}{l}\text { (1)了解恐龙起源与年代, 恐龙相关知识、进化过程科普。 } \\
\text { (2)通过科技设备, 进行白严纪光影历险, 立体感受白严纪的弱肉强食, 通过游 } \\
\text { 戏, 对恐龙特性进行定向探知。 } \\
\text { (3)在花海中通过 “五感体验法” 了解植物基本情况, 认识植物作为中草药的药 } \\
\text { 性及使用情况, 手绘植物团扇。 }\end{array}$ \\
\hline & $\begin{array}{l}\text { 河源万绿湖景区一一 } \\
\text { 《逆流而上・寻源万绿 } \\
\text { 湖》 }\end{array}$ & $\begin{array}{l}\text { (1)饮水思源: 了解深港莞惠等地 } 4000 \text { 多万人口的水源地环境, 接受水环保教 } \\
\text { 育。 } \\
\text { (2) 探寻优质水源秘密的系列活动: 环万绿湖游览, 观察万绿湖地理位置及生态 } \\
\text { 环境; 进行取水实验发现优质水源秘密; 登岛观察寻找森林公园中的动植物资 } \\
\text { 源; 品尝万绿湖有机鱼; 赏析名诗词中的新丰江。 } \\
\text { (3)游戏总结: 借助保护水源、保护生态的主题游戏内容, 进行生态文明教育。 }\end{array}$ \\
\hline \multirow{3}{*}{ 历史类 } & $\begin{array}{l}\text { 阮啸仙故居一一 } \\
\text { 《审计风云, } \\
\text { 观阮啸仙的一生》 }\end{array}$ & $\begin{array}{l}\text { 1)参观阮啸仙故居与纪念馆, 了解阮啸仙烈士抗战事迹、贡献, 学习红色文化。 } \\
\text { (2)参观周边村居, 了解客家民居的建筑文化、建筑特点、建筑布局, 认识四角 } \\
\text { 楼的独特防御地位。 } \\
\text { (3)观赏故居周边的客家风情、田园风采、荷塘美色, 感受社会主义新农村建设 } \\
\text { 新风貌, 手绘纪念品团扇。 }\end{array}$ \\
\hline & $\begin{array}{l}\text { 河源市埔前镇上村村一 } \\
\text { - 《践行红色文化, } \\
\text { 做新时代爱国有为学生》 }\end{array}$ & $\begin{array}{l}\text { 1)参观革命先烈罗焕荣故居, 学习红色文化, 同时了解上村村罗氏祠堂文化、 } \\
\text { 家风家训文化。 } \\
\text { (2)自然生物初探, 了解泥鳅的外形特点及生活环境的关系, 亲自体验 “浑水摸 } \\
\text { 鱼”一—捉泥鳅。 }\end{array}$ \\
\hline & $\begin{array}{l}\text { 河源市博物馆—— } \\
\text { 《追寻红色足迹, } \\
\text { 争当有梦少年》 }\end{array}$ & $\begin{array}{l}\text { (1)参观紫金苏区革命遗址群, 进行红色文化现场教学, 了解先辈革命事迹。 } \\
\text { (2)进行红色拓展活动: 模拟革命时期情报传输场景, 了解情报工作艰难; 模拟 } \\
\text { 革命战争时期抢滩登陆作战场景, 体会革命战士夺取战争胜利的不易。 } \\
\text { (3)重温入队仪式, 学唱红歌, 重走长征路, 进行团队拓展活动。 } \\
\text { (4)参观河源市博物馆, 充分了解河源风土人情与历史变迁。 }\end{array}$ \\
\hline \multirow{3}{*}{ 科技类 } & $\begin{array}{l}\text { 农夫山泉研学基地一一 } \\
\text { 《探秘农夫山泉, } \\
\text { 寻源万绿湖》 }\end{array}$ & $\begin{array}{l}\text { (1)巴士移动文化课堂: 预习此次研学的内容, 分享饮用水的市场调查结果。 } \\
\text { (2)现代工业探索: 在农夫山泉工厂, 品尝农夫山泉旗下饮品, 学习工艺流程、 } \\
\text { 参观生产线, 完成探索任务卡, 融合水理念, DIY 创意饮用水标签。 } \\
\text { (3)生态文明教育: 透过竹子, 认识生命, 了解自然法则, 科学探索生命之源, } \\
\text { 传递 “绿水青山就是金山银山” 理念。 }\end{array}$ \\
\hline & $\begin{array}{l}\text { 河源市航模协会—— } \\
\text { 《飞向北京, 飞向未来》 }\end{array}$ & $\begin{array}{l}\text { (1)航空静态模型讲解学习: 观赏飞机模型, 了解近代飞机种类、特点及未来发 } \\
\text { 展趋势。 } \\
\text { (2)户外水上特技飞行表演: 观摩户外水上特技飞行比赛。 } \\
\text { (3)飞机模型 DIY: 讲解模型原理, 动手实践互动体验。 }\end{array}$ \\
\hline & $\begin{array}{c}\text { 新丰江水电站一一 } \\
\text { 《饮水思源, 我是水力发 } \\
\text { 电操作员》 }\end{array}$ & $\begin{array}{l}\text { (1)通过历史图文资料, 了解新丰江电厂大坝的历史, 了解修建水库大坝选址考 } \\
\text { 虑因素。 } \\
\text { (2)参观大型水力发电机组模型, 了解水力发电的运行原理。 } \\
\text { (3)参观水力发电机组工作室, 认识发电的工作流程。 } \\
\text { (4)参观大坝位移测量室, 了解水平位移监测及垂直位移监测的工作原理及测试 } \\
\text { 方法。 } \\
\text { (5)亲手组装一个微型发电站, 并启动发电站制造电能。 }\end{array}$ \\
\hline 人文类 & $\begin{array}{c}\text { 广东客天下研学旅行管 } \\
\text { 理有限公司- } \\
\text { 《品见・客家》 }\end{array}$ & $\begin{array}{l}\text { (1)游览醉蝶谷花海, 亲近自然。 } \\
\text { (2)走进恐龙探险馆，借助现代科技获取恐龙世界的沉浸式真实体验。 } \\
\text { (3)3D 客家建筑模型搭建，深入了解客家建筑布局; 走进客家小镇，学习客家文 } \\
\text { 化，了解客家人来历、客家建筑历史。 } \\
\text { (4)学习五谷知识，了解黄豆的原型及制作豆浆的流程工序。 }\end{array}$ \\
\hline 体验类 & 四季丰研学基地一 & (1)参观知青馆，知史明理（2) “知青”生产劳动体验。 \\
\hline
\end{tabular}




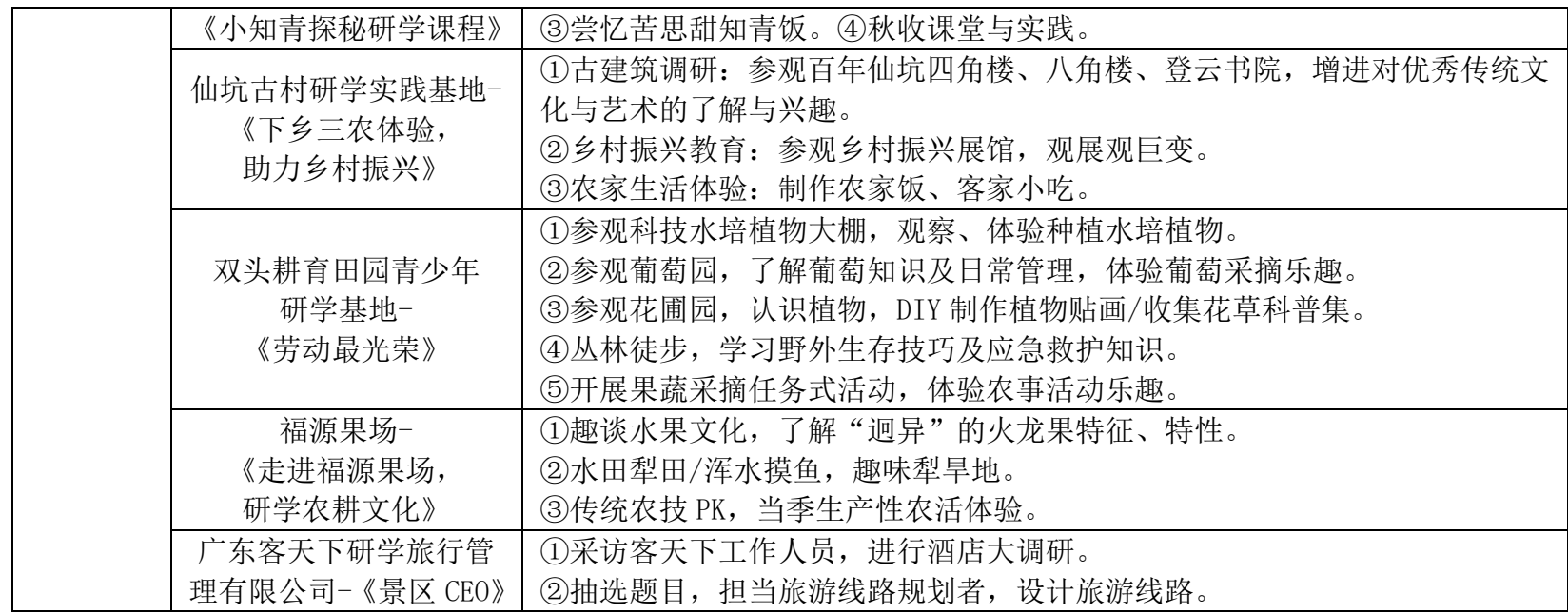

在实地访谈调研中还发现, 河源典型研学课程在 开发实践过程中也存在一些问题: 首先, 同质化课程 日益变多, 容易出现内卷倾向, 比如以 “客家文化” 为主题的课程基本都有客家建筑研学环节, 实际上有 一些研学地的客家建筑研学实施较为牵强; 其次, 研 学课程虽突出河源特色, 但设计的逻辑性、差异化、 育人力等还是有待提升。某些以 “客家文化” 为主题 的课程, 为了面面俱到, 从而涉及过多元素, 比如 “客 家文化+自然体验十恐龙文化 + 农事科普十劳动教
育” 等，衔接不清，略显冗杂，“客家文化”主题反 而淡化。课程设计普遍与校内课程缺乏链接, 部分研 学课程缺乏针对性的学段细分, 从小学到中学使用同 一套研学课程手册, 造成小学生看不懂、中学生不愿 看的情况; 最后, 高素质研学导师缺口较大也是限制 课程开发水平、实施程度、完善提升的重要因素。当 然，个体课程也有自我的优势与待完善之处，因篇幅 有限, 仅将三个典型研学旅行课程进行对比分析如下

（见表 3）。

表 3 河源市三个典型研学旅行课程对比分析表

\begin{tabular}{|c|c|c|c|}
\hline 课程名称 & 《品见・客家》 & 《下乡三农体验, 助力乡村振兴》 & 《逆流而上・寻源万绿湖》 \\
\hline 课程优势 & $\begin{array}{l}\text { 依托 } 4 \mathrm{~A} \text { 级景区、省级中小 } \\
\text { 学生研学实践教育基地, } \\
\text { 具有如下优势: } \\
\text { (1)因地制宜, 开发课程; } \\
\text { (2)设施完备, 后勤完善; } \\
\text { (3)依托景区, 口碑效应。 }\end{array}$ & $\begin{array}{l}\text { 依托第二批全国乡村旅游重点村, 具有 } \\
\text { 如下优势: } \\
\text { (1)政府支持, 名企筹建; } \\
\text { (2)师资多元，协助配合; } \\
\text { (3)场地安全，医疗专业; } \\
\text { (4)承载量大，接待周全。 } \\
\text { (5)经济社会，效益突出。 }\end{array}$ & $\begin{array}{l}\text { 依托 } 4 \mathrm{~A} \text { 级景区、中国优质饮用水 } \\
\text { 资源开发基地, 具有如下优势: } \\
\text { (1)生态优越, 资源独特; } \\
\text { (2)教学环境, 新颖独特; } \\
\text { (3)课程研发, 逻辑较好; } \\
\text { (4)课程升级, 与时俱进。 }\end{array}$ \\
\hline $\begin{array}{l}\text { 课程可 } \\
\text { 完善点 }\end{array}$ & $\begin{array}{l}\text { (1)课程逻辑衔接可改进; } \\
\text { (2)元素过多，结构冗杂， } \\
\text { 主题淡化。 }\end{array}$ & $\begin{array}{l}\text { (1)本地同类型资源较多, 同类型课程不 } \\
\text { 少, 需不断升级完善; } \\
\text { (2)课程内容的针对层次待细分。 }\end{array}$ & $\begin{array}{l}\text { (1)课程体验性内容待完善; } \\
\text { (2)教学环境存在安全隐患; } \\
\text { (3)缺乏高素养导师。 }\end{array}$ \\
\hline
\end{tabular}

\section{4. 河源市研学旅行课程的完善策略}

\section{1 政府规范管理，合理利用资源，规避无效 内耗}

近年来，河源市教育局、文化广电旅游体育局等 相关政府部门通过基地考评、课程评选等各项活动来 设置行业准入门槛, 篮选研学旅行课程, 目的就是鼓 励有实力、高品质的研学旅行课程开发方能合理利用 河源文旅资源, 不断完善课程研发, 起到行业引领与 示范作用。课程开发方应吃透自身文旅资源特色, 注 重因地制宜, 挖掘个性研学因素。以 “客家文化” 主 题为例, 以古村落遗址保存良好为优势的研学地应突 出客家建筑的研学元素, 而民俗遗存丰富的研学地则 要突出客家非遗、民俗体验等研学元素, 围绕核心元
素进行设计，做到研学目标清晰，逻辑主次分明，以 文化为线索，搭起课程的内在逻辑。各研学机构、基 地可多展开合作交流, 尤其是以类似元素为主题来开 发课程时, 从不同侧面、角度来设计课程, 既避免课 程内容过度重合, 又能实现课程衔接的共赢。在实践 运作中, 研学组织方将万绿湖景区与农夫山泉基地的

“水” 元素研学课程进行融合, 如研学时间允许, 还 可增加 “温泉水” 元素研学课程, 完善研学体验, 丰 富研学行程。

\section{2 遵循课程原则, 落实研发细节, 保障课程 效果}

研学旅行课程作为校内和校外课程相结合的一 种新形式, 虽然在开展方式上有别于传统课程, 但仍 具备课程的本质属性 ${ }^{[5]}$ 。在课程设计方面, 需要校方、 
服务机构、研学基地等多元开发主体通力合作, 既要 依托地方文旅资源特色, 也要考虑学校课程育人根本 目标, 促进研学课程与校内课程的衔接, 最终形成 “调研学生需求一一深研基地内容——校企共同设 计一一尝试检验效果——修改深化方案——形成出 行方案一一实地考察学习——反思交流体验”的课 程管理推进模式; 在研学主体方面, 把握研学主体的 特质, 准备与年龄层相符的课程内容与研学教材, 注 重与其交往的方式方法; 在研学导师方面, 一方面鼓 励经验丰富、需要转型的导游经过系统培训、学习后 加入研学导师行列, 另一方面与本地高校深入合作, 培养定制化应用型人才, 全面提高研学导师队伍综合 素养; 在研学出行方面, 要明确安全第一的要诀, 做 好规划, 保障教学水平、服务质量等。

\section{3 借鉴成熟模式，注入文化内涵，作创造性 转化}

研学课程内容的地域文化性很强, 依托于不同的 资源, 传递着风采各异的文化。纵观全国研学市场, 全国旅游大省都在向文化强省方向迈进，文旅融合之 风势不可挡。以山东为例, 既有依托丰富的博物馆资 源优势来开展小众特色博物馆主题研学, 又有东阿阿 胶世界协同济南宏济堂中医药文化园区, 开展中医药 文化研学游。立足河源, 除了以独特的万绿湖水文化、 客家建筑文化等为基底来大做课程文章, 更需要将客 家非遗技艺、生活习俗等提炼、活化成课程, 比如结 合博物馆、酒窝等开展客家糯米酒传统酿制技艺研 学, 从原料地到米粉加工厂开展客家米粉美食研学, 从茶田到茶厂开展客家擂茶研学等, 跨界联动合作, 持续创新课程。

\section{5. 结论}

研学旅行课程对于提高中小学生的综合素质, 培 养学生的社会主义核心价值观有着重要作用, 因此, 必须从研学课程本身的教育属性及科学内涵出发, 挖 掘河源本地优质的文旅资源中的研学要素来设计课 程, 同时课程的设计并非 “一劳永逸” , 必须依据各 种因素的变化来与时俱进地优化。

\section{基金项目}

广东省普通高校重点科研平台和科研项目一青 年创新人才类项目 “产业融合趋势下粤北山区温泉 文旅资源整合与品牌建设研究”（项目编号： 2018GWQNCX121）；2020 年广东省科技创新战略专项 资金 ( “攀登计划” 专项资金) 项目: 文旅融合背景 下河源研学旅游资源赋存及整合现状调研（项目编 号：pdjh 2020b1240）；2021 年广东省科技创新战 略专项资金 ( “攀登计划” 专项资金) 项目: 以云游 为平台 ・助微旅游振兴——疫情防控常态化背景下河 源微旅游与云旅游融合现状调研（项目编号： pdjh2021b0929）; 河源市哲学社会科学 “十三五” 规划 2018 年度重点项目 “产业融合趋势下河源温泉 文旅资源整合与品牌建设研究”（项目编号： HYSK18Z11）。

\section{REFERENCES}

[1] Li, Q. (2019) Research on domestic research travel courses: retrospect, reflection and prospect. Journal of Northwest Adult Education Institute, 01: 81-86.

[2] Gu,W. Hou, YH. Wang, XY. (2021) Research on the strategy of constructing the characteristic curriculum system of research and study travel in primary and middle schools. Journal of Handan University, 31(02):109-113.

[3] Zhu,WQ. (2019) Research on the development of research and study travel under the background of cultural and travel integration. Journal of Qiqihar Teachers College, 04:30-31.

[4] Fang,YP. Bi, DD. Gan, QL. (2008) Research on the development mode of cultural tourism resources in Heyuan City. Tropical geography, 05:483-487.

[5] Yu,FB. Yang, DJ. (2021) Classification and design of research travel courses based on core literacy. Basic Education Course, 14:4-10. 